\section{A SIMPLE FORM OF FREEZING SECTION} MACHINE.

BY URBAN PRITCHARD, M.D., F.R.C.S., PATHOLOGICAL REGISTRAR TO KING'S COLLEGE, LONDON, AND SURGHON
TO THE ROXAL KAR DISPBNSAY, SOHO.

The difficulty of cutting thin sections of soft tissues has for many years past been acknowledged by histologists, and several methods have from time to time been suggested for solving the vexatious problem. Hardening the tissue by means of certain reagents, such as alcohol, chromic acid, \&c., is the plan that is usually followed, and it is one, too, that answers well under ordinary circumstances. Frequently, however, it is desirable to cut the tissue in its fresh state, especially in the case of pathological structures, and for this reason the idea of freezing the tissue was projected. In the Journal of Anatomy and Physiology for May, 1871, Professor Rutherford described his excellent machine for this purpose, which is a modification of Stirling's microtome, with the addition of a surrounding ice-box. This form of machine is very useful, as I have found from considerable experience; but it necessarily requires much time and care in its use, and it was with a view to render the instrument simpler and more rapid in its action that $I$ designed the little apparatus I will now describe.
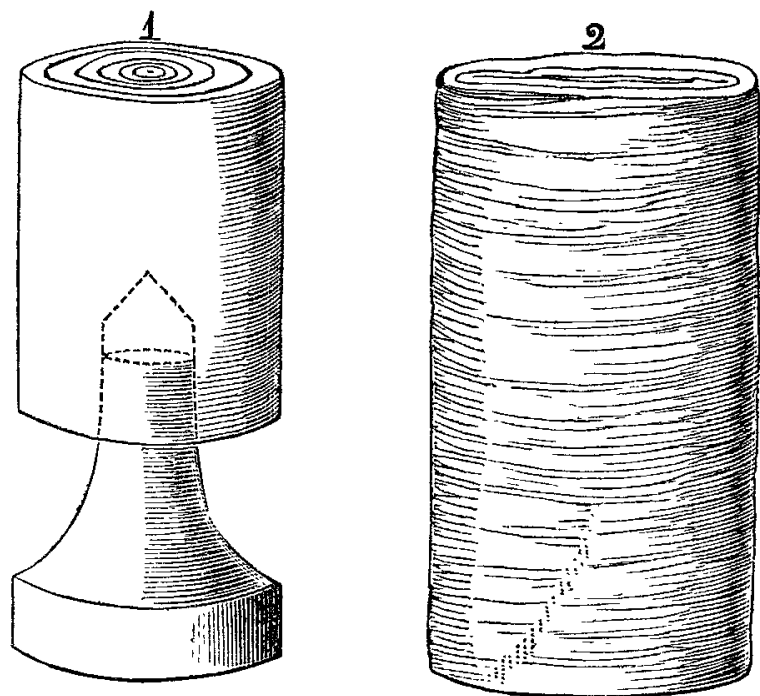

It consists of two pieces-(1) a metallic cylinder fitted with a wooden handle; (2) a cap of thick felt.

(1) The metallic cylinder, which is solid throughout, should be made of copper on account of its conductivity, but gun metal, or even brass, will answer the purpose sufficiently well. Its exact size or shape is not of very much consequence, so long as it is large enough and convenient to handle. The following dimensions I recommend: diameter of metal cylinder $1 \frac{3}{8}$ inch, length $1 \frac{3}{4}$ inch; the diameter of the end of the wooden handle $(b)$ should also be $1 \frac{3}{8}$ inch; the plug end should taper gradually, and the hole in the metal be a deep one, so that the plug may be pushed further in when the metal contracts on cooling. Both the wooden and metallic ends are made flat, so that the instrument can stand on either extremity; on the metal surface are a series of half a dozen concentric shallow grooves.

(2) Is simply a cap of thick felt, such as is used for boilers being preferable, made so as to fit somewhat loosely over the machine (1).

Mode of using the machine.-Plunge (1) with metallic face downwards into a mixture of finely pounded ice and salt; af ter remaining therein for three or four minutes, take it out and wipe with a clean cloth. The instrument has now been cooled down far below the freezing point, and on placing upon the metal plate a piece of soft tissue, this immediately freezes to the machine. The cap (2) must now be placed over the metal, but not allowed to touch the tissue, which will then freeze throughout in a very short space of time, varying according to the size of the tissue from a few seconds to one or two minutes. Now reverse the cap so as to leave the metallic top free, and, holding the whole in the left hand, cut the sections with the right by means of a sharp razor which has been kept cool in ice-and-water. Occasionally, the tissue may slip on the metal; when this is the case, remove the preparation, moisten it with gumwater, and replace it, when it will be found to adhere with much greater firmness. This slipping, however, very rarely occurs with perfectly fresh tissues, the grooves on the metallic surface tending to prevent it. The tissue will remain frozen quite long enough to make several score of sections, but should a thawing action set in, it may be covered with thin gutta-percha, and the machine again plunged into the ice-and-salt.

The advantages of this little machine are, first of all, its simplicity; and, secondly, the rapidity with which tissues may be frozen by its means. To illustrate the quickness of its action, it is only necessary to drop a little water on the cooled metal to convert it immediately into ice. Lastly, the apparatus may be made by any instrument maker or metal turner for a few shillings.

Mr. Baker, of Holborn, and Mr. Swift, of Universitystreet, are manufacturing these machines.

To those who are specially interested in the subject, I may mention that I propose showing the little instrument in action at the next meeting of the Medical Microscopical Society (Dec. 17th)

Guildford-street, Russell-square, W.C.

\section{CASE OF FIBROID TUMOUR OF THE MASSETER MUSCLE.}

\author{
BY KELBURNE KING, F.R.C.S., \\ SURGEON TO THI HULL GRNRRAX INFIRMABY.
}

JoHx $S-$ aged thirty-two, was admitted into the Hull Infirmary on March 2nd, 1872, under the following circumstances. For two years he had noticed a hard swelling in the region of the left temple, which extended down to the back of the left cheek. It was of slow growth, but as it grew he became unable to open his mouth, and, after the end of six months, he could separate his jaws only sufficiently to admit the thickness of a match. Latterly he had lost even this slight power of separation. His jaws were immovably fixed, and he lived entirely by suction through interstices between the teeth. He followed his employment as a labourer in a ship-building yard as long as he could, but of late be became so weak through insufficient nourishment that he was compelled to leave his work and apply for relief.

On admission, a hard lump, about the size of a damson plum, was felt in the centre of the masseter muscle, and another less distinct in the temporal, about an inch above the zygoma. The tumours had the feeling of enlarged, violently contracted muscular masses. Thinking it possible that the disease might depend on hypertrophy and permanent contraction of the muscles, I immediately administered chloroform, and, that failing to produce any relaxation, I divided the masseter subcutaneously. A certain amount of relief was afforded, and the jaws could be separated so far as to admit the patient's finger.

This mitigation was not permanent. On March 30 th the closure was again complete. Chloroform was administered, and subcutaneous section of both muscles was performed. Some temporary relief followed, but the advantage gained was lost by degrees.

It was now evident that some other proceeding must be resorted to for his relief. The swelling was now most marked in the temporal region, and I resolved to remove the zygomatic process, so as to relieve the tension of the masseter, and get access to the insertion of the temporal muscle.

Accordingly on May 1st I performed the following operation :-An incision was made over the zygomatic arch, from the prominence of the cheek bome to almost half an inch in front of the ear. Auother incision was made at right angles to this, extending about an inch above and below it. The flaps were dissected back, the masseter divided from the lower and the temporal from the upper margin of the zygoma. The bone forceps were then applied to the anterior and posterior extremities of the arch, which was removed. The 